\title{
Changes in attainment of lipid goals by general practitioners and specialists in patients at high cardiovascular risk in Hungary during 2004-2008
}

Laszlo Mark ${ }^{1}$ György Paragh², Istvan Karadi ${ }^{3}$ Istvan Reiber ${ }^{4}$, Gyula Pados $^{5}$

\author{
12nd Department of Internal Medicine - Cardiology, Pandy Kalman Bekes County Hospital, \\ Gyula, Hungary \\ $21^{\text {st }}$ Department of Medicine, Medical and Health Science Centre, University of Debrecen, \\ Debrecen, Hungary \\ 33rd Department of Medicine, Semmelweis University, Budapest, Hungary \\ $44^{\text {th }}$ Department of Medicine, St. George Fejer County Hospital, Szekesfehervar, Hungary \\ 5Independent Department of Lipidology, St. Imre Hospital, Budapest, Hungary
}

Submitted: 10 August 2010

Accepted: 26 August 2010

Arch Med Sci 2010; 6, 5: 695-700

DOI: 10.5114 /aoms.2010.17083

Copyright (c) 2010 Termedia \& Banach

\section{Abstract}

Introduction: Lipid-lowering therapy should achieve target levels. We assessed the change of the achievement of targets and the mean low-density lipoprotein cholesterol (LDL-C) levels in high-risk Hungarian patients.

Material and methods: Six studies performed with patients of general practitioners (GPs) and specialists between 2004 and 2008 were evaluated: 9,508 patients from GPs and 2809 from specialist practices (total 12,317).

Results: During this 4-year period the LDL-C level decreased by $0.73 \mathrm{mmol} / /$ and the LDL-C goal achievement rate increased from 14 to $32 \%$ in patients treated by GPs. LDL-C showed a decrease of $0.48 \mathrm{mmol} / /$ and the goal achievement rate changed from 20 to $43 \%$ in patients treated by specialists. In the majority of the patients not achieving the LDL-C goal (57\% for specialists and $89 \%$ for GPs) there was no modification in the current therapy. In addition to emphasizing the priority of LDL-C lowering, we should also strive for residual risk reduction, which means raising high-density lipoprotein cholesterol (HDL-C) and lowering triglyceride levels. There was no significant improvement in $\mathrm{HDL}-\mathrm{C}$ or triglyceride levels during the examined period.

Conclusion: More attention needs to be paid to changing treatment of patients to achieve target levels.

Key words: prevention, risk factors, hypercholesterolaemia, statins, LDL cholesterol.

\section{Corresponding author:} Laszlo Mark MD, PhD $2^{\text {nd }}$ Department of Internal Medicine - Cardiology Pandy Kalman Bekes County Hospital

Semmelweis u. 1., P.O. Box 46 5701 Gyula, Hungary

Phone: 36209288053

Fax: 3666526543

E-mail: mark@pandy.hu

\section{Introduction}

Cardiovascular (CV) diseases are the main cause of death in adults although in Western Europe and the USA a slight and continuous improvement has been observed for several decades. In Hungary this tendency began in 1993 and during the last 15 years life expectancy at birth has increased by 4.14 years; reduced CV mortality contributed to this improvement by 1.85 years [1].

Life expectancy increased by 6 years between 1970 and 2000 in the USA, and 3.9 years of that increase can be attributed to reductions in CV disease mortality. Three quarters of the decline in coronary heart disease 
(CHD) mortality was due to secondary prevention and other improvements in treatment, with primary prevention accounting for only one quarter [2].

The Finnish database system made it possible to analyse the reasons behind the $63 \%$ improvement in CHD mortality between 1982 and 1997. Nearly one quarter $(23 \%)$ of this result is attributable to improved therapeutic interventions (resuscitation, fibrinolysis, percutaneous coronary intervention and bypass surgery). The majority of the improvement (53-72\%) was achieved through the reduction of risk factors (cholesterol, hypertension, smoking), and the treatment of elevated lipid levels was especially effective (37\%) [3]. Similarly, results from other countries have shown the close relation between risk factor changes and occurrence of CV diseases [4, 5].

Reduction of total cholesterol and low-density lipoprotein cholesterol (LDL-C) level significantly lowers the incidence of CV events, as evidenced by primary and secondary prevention trials [6]. Statins are the first-line medications in lipid-lowering therapy. According to data obtained from meta-analyses, the reduction of LDL-C levels by $1 \mathrm{mmol} / \mathrm{l}$ results in a $12-15 \%$ decrease in total mortality and a $19-28 \%$ decrease in mortality related to $\operatorname{CHD}[6,7]$.

Based on the results of clinical trials it can be concluded that a greater LDL-C lowering results in a greater reduction of CV events [8]. In the light of these data, prevention consensus conferences in Hungary determined different risk categories and the associated therapeutic goals to be achieved for more efficient medical care [9]. Subsequently, general practitioners (GPs) and specialists were informed via journals, at scientific congresses and symposia in order for these guidelines to be implemented in routine clinical practice. Currently, statins are administered to more than 600,000 patients in Hungary (partly due to available generic statins) [10].

We assessed how more efficiently applied lipidlowering therapies changed patient mean lipid levels.

\section{Material and methods}

Data of studies published in Hungary between 2004 and 2008 were used (CEL Program 2004 and 2005 [11], KONSZENZUS-CEL Program 2006 [12], REALITY 2004 and 2007 studies [13-15] and MULTI GAP 2008 [16]). These studies assessed the effect of treatment of patients in GPs and specialist practices. The evaluation of the high-density lipoprotein cholesterol (HDL-C) was not a criterion to participate in these studies. In the present survey only patients with a history of a CV event and on a lipid-lowering therapy for at least 1 month were enrolled and we excluded those in whom the LDL-C calculation was not possible (no HDL-C available or triglyceride level > $4.5 \mathrm{mmol} / \mathrm{l}$ ).
In the series of the CEL Program [11] primary care physicians were made aware of the current consensus recommendations, and subsequently the broader use of guidelines and the adoption of an up-to-date CV therapeutic approach were promoted. GPS willing to participate after a preliminary survey were educated using centrally provided information by 4 national and the countylevel coordinators. Patient eligibility criteria were known CV disease or asymptomatic individuals with at least 2 risk factors. In the CEL Program 2004 [11] 18,142 patients of 320 GPs participated, and data of a subgroup of 15,404 were assessed during a 3-month follow-up period, and 6,455 were enrolled in the present survey [10]. In CEL 2005 [12] 12,101 patients of 200 GPs and in KONSZENZUS-CEL Program 2006 [12] 11,826 patients of 68 GPs were enrolled; 993 and 505 could participate in the present study. Treatment strategies of the last 1015 patients with CV events treated by 79 internists, 48 diabetologists, 61 cardiologists, 42 neurologists and 53 GPs were assessed retrospectively in the MULTI-GAP study [16]. In total, the results of 4214 patients were entered anonymously into the present analysis database: 523 from the GP group and 1466 from the specialist group.

The REALITY studies [13-15] were conducted in 2004 and November 2007. From the results of the year 2004, the data of 440 patients on lipidlowering therapies were evaluated, 10 patients being enrolled per physician: 300 patients were treated by GPs and 140 by specialists; 201 and 120 could participate in the present survey $[13,14]$. In the REALITY study conducted in 2007 [15], 4214 patients were enrolled: 784 patients were treated by GPs, and 523 were considered in the present survey. From the 911 patients of 61 cardiologists, 1175 patients of 79 internists, 719 patients of 48 diabetologists and 625 patients of neurologists, 1466 participated in the present study [14]. Altogether the data of 9,508 patients from GPs and 2,809 from specialist practices (total 12,317) were evaluated. Table I shows the distribution and numbers according to the year of the investigation.

The risk stratification of patients was done according to the $3^{\text {rd }}$ Hungarian Therapeutic Consensus Conference [9]. All the patients were at least at high risk with a history of a CV event. The target LDL-C value was $2.5 \mathrm{mmol} / \mathrm{l}$. We know that some of the participants were at very high CV risk (with a $1.8 \mathrm{mmol} / / \mathrm{LDL}-\mathrm{C}$ target level) but because of the lack of sufficient data their retrospective definition was not possible. $3.0 \mathrm{mmol} / \mathrm{l}$ would be the target value in patients at high risk but without symptoms of atherosclerosis.

The study was conducted in accordance with the Declaration of Helsinki and ICH-GCP (International 
Table I. Size of patient populations compared across the studies

\begin{tabular}{|lccccc|}
\hline & $\begin{array}{c}\text { CEL 2004 } \\
\text { REALITY 2004 }\end{array}$ & CEL 2005 & $\begin{array}{c}\text { KONSZENZUS-CEL } \\
\text { Program 2006 }\end{array}$ & REALITY 2007 & $\begin{array}{c}\text { MULTI GAP } \\
\text { 2008 }\end{array}$ \\
\hline General practitioner & $6455+201$ & 993 & 505 & 831 & 523 \\
\hline Specialist & 120 & & & 1223 & 1466 \\
\hline
\end{tabular}

Conference on Harmonisation - Good Clinical Practice). Informed consent was obtained from each subject.

\section{Statistical analyses}

Descriptive statistics are presented as frequencies and percentages for categorical variables and as the mean values \pm SD for continuous variables. Because of the skewed distribution, TG levels are presented as median and interquartile range and were log-transformed before statistical testing. Categorical variables were compared using the $\chi^{2}$ test. Paired Student's $t$-test was used for continuous parametric variables. Wilcoxon signed-rank test was used for continuous variables that were not normally distributed. All tests were two-sided, and $p$ values $<0.05$ were considered statistically significant. Statistical analyses were performed with SPSS 7.5

\section{Results}

There was a significant change in mean lipid parameters of patients treated by GPs in the past 5 years, mainly reflected by the reduction of mean LDL-C levels.

In the CEL Program 2004, as a result of the therapy of patients with a prior CV event a mean LDL-C level of $3.78 \mathrm{mmol} / \mathrm{I}$ was achieved, which is surprisingly high, i.e. far above the desired level of $2.5 \mathrm{mmol} / \mathrm{l}$. There was a significant improvement in LDL-C levels during the next 4 years, with a mean value of $3.05 \mathrm{mmol} / \mathrm{l}$ in 2008. Efficiency of the treatment improved by $0.73 \mathrm{mmol} / \mathrm{l}$ during the examined 5-year period (Figure 1). If this tendency continues, the mean value will be closer to the target of $2.5 \mathrm{mmol} / \mathrm{l}$, but will still not reach it in the next 3 years.

Three studies were available addressing the efficacy of lipid-lowering therapies in patients with prior CV events treated by specialists. Mean LDL-C level of treated patients was $3.34 \mathrm{mmol} / \mathrm{l}$ in 2004, whereas it was $2.85 \mathrm{mmol} / \mathrm{l}$ in the MULTI GAP study in 2008, a value much closer to the target of $2.5 \mathrm{mmol} / \mathrm{l}$. The absolute change of nearly $0.5 \mathrm{mmol} / \mathrm{l}$ shows a significant improvement over 5 years (Figure 1).

The change of treatment efficacy is specially marked if LDL-C distribution of treated patients is studied (Figure 2). Data of CEL Program 2004 show a Gaussian curve and despite the treatment the proportion of patients below $2.5 \mathrm{mmol} / \mathrm{l}$ is apparently very low. 2008 brought a left shift of the distribution curve. Area under the curve of the target value is about double that of 2004 . The proportion of patients with LDL-C over $3 \mathrm{mmol} / \mathrm{l}$ $3.0 \mathrm{mmol} / \mathrm{l}$ would be the target value in high-risk patients without symptoms [9] - at GPs remained high; it was $72 \%$ in 2004, and despite the considerable improvement, $51 \%$ in $2008.1 .8 \mathrm{mmol} / \mathrm{l}$ (the target value for patients at very high risk, which has major implications for the progression of atherosclerosis), was achieved in 2004 in only $5 \%$ of the patients, whereas in 2008 it was achieved in $20 \%$.

Two-year data are available about the distribution of LDL-C levels of patients treated by specialists and these data show a significant difference even within such a short period of time.

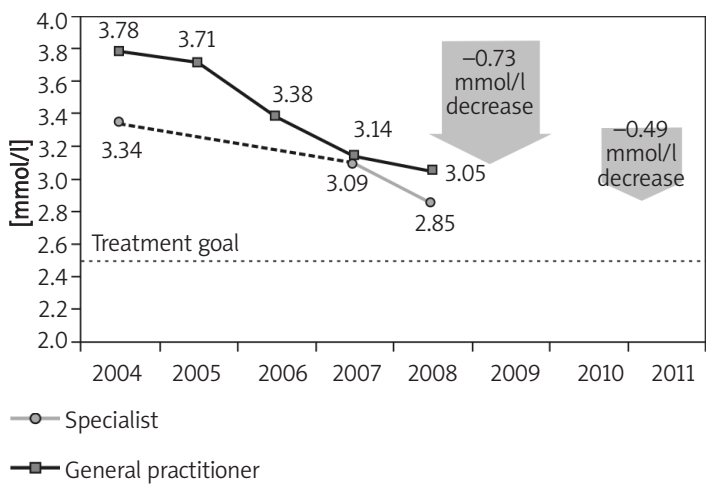

Figure 1. Change in mean LDL cholesterol levels of patients at high CV risk treated by GPs and specialists over the years

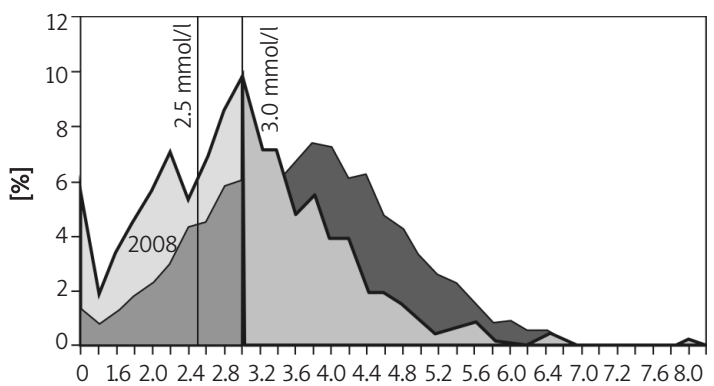

Figure 2. Distribution of LDL cholesterol levels of patients at high risk treated by GPs over the years 


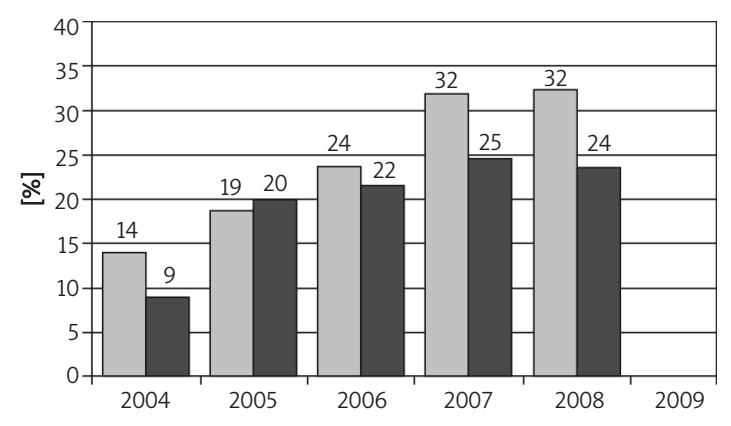

$\square$ LDL-C

$\square$ Total cholesterol

Figure 3. The improvement of LDL cholesterol and total cholesterol goal achievement in patients at high risk treated by GPs over the years

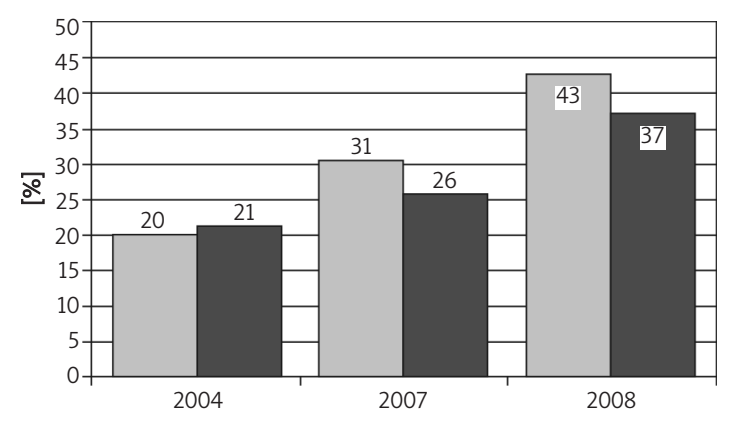

$\square \mathrm{LDL}-\mathrm{C}$

- Total cholesterol

Figure 4. Distribution of LDL cholesterol and total cholesterol goal achievement in patients at high risk treated by specialists over the years

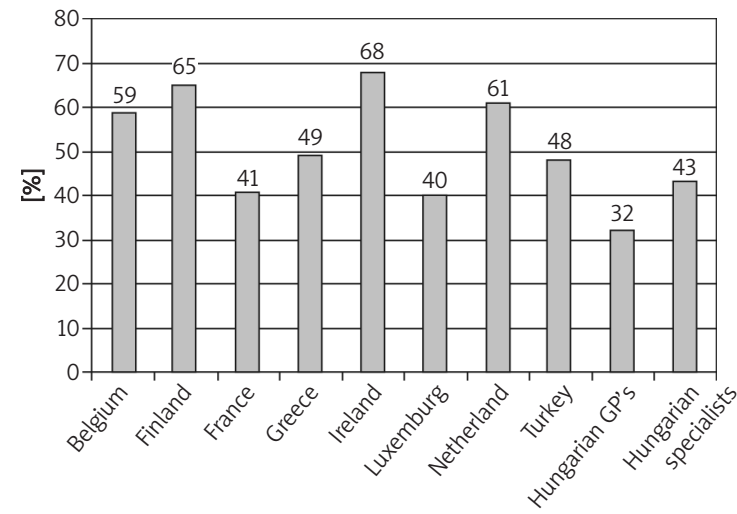

Figure 5. Comparison of LDL cholesterol goal achievement in the countries of the CEPHEUS study and the present study

Forty-one percent of patients had an LDL-C value below $2.5 \mathrm{mmol} / \mathrm{l}$ in 2008; 19\% of them also achieved the target value of $1.8 \mathrm{mmol} / \mathrm{l}$. At the same time $37 \%$ of patients at high risk cared by specialists required further therapeutic intervention, because even after treatment their LDL-C levels remained above $3.0 \mathrm{mmol} / \mathrm{l}$.
Fourteen percent of patients at high CV risk treated by GPs achieved the guideline goal of $2.5 \mathrm{mmol} / \mathrm{L} \mathrm{LDL}-\mathrm{C}$ in 2004, and this percentage was improved to $32 \%$ by 2008 . Those achieving the total cholesterol goal of $4.5 \mathrm{mmol} / \mathrm{l}$ improved from $9 \%$ to $24 \%$ (Figure 3).

Patients treated by specialists achieving the LDL-C goal value of $2.5 \mathrm{mmol} / / \mathrm{improved}$ from $20 \%$ to $43 \%$ over 5 years, and also achievement of the total cholesterol goal value showed a favourable tendency (Figure 4).

In Hungary between 2004 and 2008 a progressively higher proportion of patients treated by GPS and specialists achieved target LDL-C values. But in $57 \%$ of patients treated by specialists and $89 \%$ of them treated by GPs the insufficient treatment was not modified in those with lipid values above the target level in 2008 [16].

Regarding the lipid-lowering therapy, simvastatin was the most frequently prescribed (72\%) by GPs in 2004, whereas in 2008 atorvastatin was in the first place (46\%) and $7 \%$ of the patients received rosuvastatin. At the same time, combination treatment also became more frequent (12\%) by 2008, using the cholesterol absorption inhibitor ezetimibe. Specialists applied more aggressive treatment with higher doses of statin and more combination therapies (29\%).

Triglyceride levels did not change as significantly as LDL-C levels. GP patients experienced a reduction of $0.3 \mathrm{mmol} / \mathrm{l}$ of the average value (from $2.3 \mathrm{mmol} / \mathrm{l}$ to $2.0 \mathrm{mmol} / \mathrm{l}$ ) between 2004 and 2008. There was no difference in the efficacy of triglyceride treatment between GPs and specialists (specialists also had a reduction of the mean value from $2.3 \mathrm{mmol} / \mathrm{l}$ to $2.0 \mathrm{mmol} / \mathrm{l})$.

An unfavourable change was observed in $\mathrm{HDL}-\mathrm{C}$ levels of the GP patients (the mean level declined from $1.37 \mathrm{mmol} / \mathrm{l}$ to $1.30 \mathrm{mmol} / \mathrm{l})$. At the same time it showed an increase from $1.2 \mathrm{mmol} / \mathrm{l}$ to $1.3 \mathrm{mmol} / \mathrm{l}$ in patients followed up by specialists.

\section{Discussion}

Cardiovascular prevention is undergoing a substantial transformation. The importance of emergency care is indisputable, but it is already evident that CV morbidity and mortality can be significantly modified by the application of prevention guidelines [9]. The everyday prevention activity is determined by these guidelines, of which one of the most important fields is lipid-lowering therapy, which is facing a qualitative change. It is important that all patients in need receive lipid-lowering therapy but more and more attention has to be paid to goal achievement as this may cause an optimal reduction of events. The change in lipid-lowering therapy and lipid target value achievement between 2004 and 2008 in 12,317 high-risk Hungarian 
patients was examined in a meta-analysis of four different studies.

The $0.7 \mathrm{mmol} / \mathrm{l}$ decrease in LDL-C level in patients treated by GPS was a result of the improvement of therapy over the 5 years and was associated with a significant risk reduction in these secondary prevention patients. A meta-analysis published in 2007 [6] based on 261,616 patients showed that $1.0 \mathrm{mmol} / \mathrm{L} \mathrm{LDL}-\mathrm{C}$ reduction was associated with a $27 \%$ reduction of CV morbidity and a $28 \%$ reduction of mortality. Therefore, a $20 \%$ relative risk reduction can be expected from improvement of the lipid-lowering strategy by GPs. It is difficult to judge the effect of this reduction on the Hungarian morbidity and mortality measures, but it is coincident with the favourable trend [1].

The improvement of results can be explained by many factors. Besides consensus conferences held every 2 years and emphasizing guidelines issued at these conferences and international recommendations, regular education, publications and also the change in therapeutic strategies contributed to the higher proportion of goal achievement. It has to be emphasized that even during this relatively short period a substantial change in the statin therapy was observed: the use shifted from simvastatin to atorvastatin and rosuvastatin. At the same time, combination treatment also became more frequent by 2008 : $12 \%$ in GPs', and $29 \%$ in specialists' patients. Differences in LDL-C values of these two groups are due to more combination therapies used and stronger lipid-lowering therapies that are more readily available to specialists (i.e. in Hungarian clinical practice only specialists can make a recommendation to use these). A further limitation to therapeutic efficacy might have been patient adherence and persistence, which were not examined in this study.

Hermans et al. [17] have studied the LDL-C goal achievement rate according to the European guidelines of 2003 (Third Joint Task Force) in 14,478 patients treated with lipid-lowering drugs in 8 countries in the Centralized Pan-European survey on the under-treatment of hypercholesterolaemia (CEPHEUS). In a population with a mean age of 63.2 years with $45 \%$ women the goal was achieved in $55.3 \%$ of the patients in 2006-2007. The rates in the different countries are presented in Figure 5, which also shows the target level attainment in the present Hungarian patients treated by GPS and specialists. The comparison should be made with caution as the design of the 2 studies is not the same, but it is obvious that in Hungary there is a lot to do in this field.

A French study performed upon the WHO MONICA survey ascertained a $5.7 \%$ decline in the LDL-C level between 1996 and 2007 among 35-64 year old people $(p<0.001)$. The reduction was marked in the 55-64 year old group, $10.8 \%$ in men, $8.4 \%$ in women. At the same time, for triglyceride levels a $7.8 \%$ elevation was found $(p<0.001)$. In the patients receiving lipid-lowering drugs the LDL-C decrease was $17.6 \%(p<0.001)$ [18].

In the EUROASPIRE studies in Hungary a better goal achievement rate was described $(2.5 \mathrm{mmol} / \mathrm{l}$ LDL-C attained in $40 \%$ of the patients) $[19,20]$. These surveys were conducted in academic hospitals and the study population was not representative. We believe that our results are more characteristic of the Hungarian real life.

Besides the achievement of an optimal LDL-C level [21], a new goal is the reduction of residual risk by the elevation of low HDL-C levels and reduction of high triglyceride levels [22]. Not very favourable changes have been seen in this field since 2004 : only a $0.3 \mathrm{mmol} / \mathrm{l}$ reduction of the triglyceride level accompanied by a reduction of the HDL-C level. These results set the further course of lipid-lowering therapy, i.e. beside efforts made to achieve the target LDL-C values, more attention has to be paid to increasing HDL-C levels and reducing triglyceride levels. The changes observed in the present study (i.e. a very slight decrease of triglyceride level and a non-concordant change in HDL-C level) could be explained by the fact that up to now no attention was focussed on the residual lipid risk, and the primary goal was LDL-C lowering. This assumption is supported by the study of Ferrières et al. [18], where beside the favourable changes in LDL-C, a $7.8 \%$ increase of triglyceride level occurred.

In conclusion, our survey highlights a favourable improvement in lipid-lowering therapy in the last 5 years in Hungary, but the suboptimal rate of the LDL-C goal attainment also has to be emphasized. How could we further improve our treatment?

The use of more potent statins and the widespread application of combination therapy could result in more common LDL-C goal attainment. In the majority of the patients not achieving the LDL-C goal (57\% of specialists' and $89 \%$ of GPs' patients) there was no modification in the current therapy. Knowing this fact, the most important task for the near future is to pay more attention to changing the therapy of patients presenting lipid values over the target levels at follow-up visits. And beside the LDL-C reduction, for controlling the total lipid profile, more attention has to be paid to elevated triglyceride and low HDL-C levels too.

\section{Acknowledgments}

The various studies analysed in this paper were conducted by Dendrite Ltd, Hungary. This material was written independently, and no company or institution supported the authors financially. No 
professional writer was involved. All authors had full access to all the data in the study, take responsibility for the integrity of the data and the accuracy of the data analyses, and agreed to the manuscript as written. The authors have given talks, attended conferences and participated in other trials or advisory boards sponsored by various pharmaceutical companies.

\section{References}

1. Józan P. Crisis and renewal in the epidemiological evolution after the second world war in Hungary. First edition. MTA Társadalomkutató Központ, Budapest, 2008.

2. Lenfant C. Clinical research to clinical practice - lost in translation? N Engl J Med 2003; 349: 868-74.

3. Laatikainen T, Critchley J, Vartiainen E, et al. Explaining the decline in coronary heart disease mortality in Finland between 1982 and 1997. Am J Epidemiol 2005; 162: 764-73.

4. Björck L, Rosengren A, Bennett K, et al. Modelling the decreasing coronary heart disease mortality in Sweden between 1986 and 2002. Eur Heart J 2009; 30: 1046-56.

5. Delavari A, Kelishadi R, Forouzanfar MH, Safaei A, Birjandi F, Alikhani S. The first cut-off points for generalized and abdominal obesity in predicting lipid disorders in a nationally representative population in the Middle East: The National Survey of Risk Factors for Non-Communicable Diseases of Iran. Arch Med Sci 2009; 5: 542-9.

6. Gould AL, Davies GM, Alemao E, Yin DD, Cook JR. Cholesterol reduction yields clinical benefits: meta-analysis including recent trials. Clin Ther 2007; 29: 778-94.

7. Baigent C, Keech A, Kearney PM, Blackwell L, Buck G, Pollicino C; Cholesterol Treatment Trialists' (CTT) Collaborators. Efficacy and safety of cholesterol-lowering treatment: prospective meta-analysis of data from 90056 participants in 14 randomised trials of statins. Lancet 2005; 366: 1267-78.

8. Cannon CP, Braunwald E, McCabe CH, et al. Intensive versus moderate lipid lowering with statins after acute coronary syndromes. N Engl J Med 2004; 350: 1495-504.

9. The III. Hungarian Cardiovascular Consensus Conference on the risk stratification, prevention and treatment of the diseases of coronary, cerebral and periferial arteries. Metabolizmus 2008; 6 (Suppl. A): 1-99.

10. Paragh G, Pados G, Karádi I, Romics L, Szollar L. Lipid disorders. Commendations of the Hungarian Atherosclerosis Society. Útmutató. Klinikai irányelvek kézikönyve. Kardiológia. 2010.

11. Pados G, Karadi I, Paragh G, Zamolyi K. The CEL program on the therapeutic consensus. CÉL program a terápiás konszenzus megvalósításáról. Metabolizmus 2009; (Suppl. B): B8-B11.

12. Paragh G, Pados G, Karadi I, Mark L. Crossfire to cholesterol lowering therapy. Goal attainment in CEL Program. Metabolizmus 2008; 6 (Suppl. D): D10-D13.

13. Mark L, Zamolyi K, Pados G, Paragh G, Ofner P. Achieving the target lipid levels in Hungary, 2004. Orv Hetil 2005; 146: 147-52.

14. Paragh G, Mark L, Zamolyi K, Pados G, Ofner P. Lipid-modifying therapy and attainment of cholesterol goals in Hungary: the return on expenditure achieved for lipid therapy (REALITY) study. Clin Drug Investig 2007; 27: 647-60.

15. Zámolyi K, Reiber I, Kalina A. The reality in lipid lowering therapy - The REALITY study 2004 versus 2007. Metabolizmus 2008; 6 (Suppl. C): C3-6.
16. Reiber I, Paragh Gy. Achieving the lipid goals in the Hungarian MULTI GAP (multi goal attainment problem) the results of a new study on the administration and effectiveness of lipid lowering therapy. Metabolizmus 2009; 7: 69-72.

17. Hermans MP, Cabezas MC, Strandberg T, et al. Centralized Pan-European survey on the under-treatment of hypercholesterolaemia (CEPHEUS): overall findings from eight countries. Curr Med Res Opin 2010; 26: 445-54.

18. Ferrières J, Bongard V, Dallongeville J, et al. Trends in plasma lipids, lipoproteins and dyslipidaemias in French adults, 1996-2007. Arch Cardiovasc Dis 2009; 102: 293-301.

19. Kotseva K, Wood D, De Backer G, Dirk De Bacquer, Pyörälä K, Keild U; EUROASPIRE Study Group. EUROASPIRE III: a survey on the lifestyle, risk factors and use of cardioprotective drug therapies in coronary patients from 22 European countries. Eur J Cardiovasc Prev Rehabil 2009; 16: 121-37.

20. Kotseva K, Wood D, De Backer G, De Bacquer D, Pyörälä K, Keil U; EUROASPIRE Study Group. Cardiovascular prevention guidelines in daily practice: a comparison of EUROASPIRE I, II, and III surveys in eight European countries. Lancet 2009; 373: 929-40.

21. Angelopoulos J, Krassakopoulos N, Nathanson R, Boukas S, Sampalis JS. Co-administration of ezetimibe and a statin in management of dyslipidemias: a meta-analysis of clinical trials. Arch Med Sci 2009; 5: 347-63.

22. Fruchart JC, Sacks F, Hermans MP, et al. The Residual Risk Reduction Initiative: a call to action to reduce residual vascular risk in patients with dyslipidemia. Am J Cardiol 2008; 102 (Suppl.): 1K-34K. 